\title{
Citologia aspirativa no diagnóstico da linfadenite em ovinos ${ }^{1}$
}

\author{
Márcio G. Ribeiro ${ }^{2 *}$, Alexandra F. Belotta ${ }^{2}$, Marta C. Fernandes ${ }^{2}$, Rafael Guena ${ }^{2}$, \\ Geraldo de Nardi Júnior ${ }^{3}$, Gustavo H.B. Lara², Rogério Giuffrida ${ }^{4}$ \\ e Thiago de O. Zamprogna ${ }^{2}$
}

\begin{abstract}
Ribeiro M.G., Belotta A.F., Fernandes M.C., Guena R., Nardi Júnior G., Lara G.H.B., Giuffrida R. \& Zamprogna T.O. 2011. [Fine needle aspiration in diagnosis of lymphadenitis in sheep.] Citologia aspirativa no diagnóstico da linfadenite em ovinos. Pesquisa Veterinária Brasileira 31(10):839-843. Departamento de Higiene Veterinária e Saúde Pública, Faculdade de Medicina Veterinária e Zootecnia, Universidade Estadual Paulista, Cx. Postal 560, Botucatu, SP 18618-970, Brazil. E-mail: mgribeiro@fmvz.unesp.br

The fine needle aspiration in diagnosis of lymphadenitis in sheep, and occurrence of microorganisms in the lymph nodes, with emphasis to identification of Corynebacterium pseudotuberculosis were investigated. One hundred sheep with lymphadenitis and 100 lymph nodes without lesions collected from sheep in slaughterhouses were evaluated. $C$. pseudotuberculosis (73.0\%), Arcanobacterium pyogenes (6.0\%), Streptococcus spp. $\beta$ hemolytic (5.0) and Escherichia coli (4.0\%) were the more frequent causal agents in sheep with lymphadenitis. Streptococcus spp. (21.0\%) and Staphylococcus spp. (7.0\%) were the more common microorganisms identified in lymph nodes without lesions sampled in slaughterhouse. Fine needle aspiration enable identify 79 (79.0\%) microorganisms with "corynebacteria" aspect in sheep with lymphadenitis. From these, 73 (73.0\%) were identified as C. pseudotuberculosis. None strain of $C$. pseudotuberculosis was isolated from lymph nodes of animals without lesions. The results showed the high frequency of $C$. pseudotuberculosis in sheep with lymphadenitis, and possibility the use of fine needle aspiration in initial diagnosis of lymphadenitis in sheep.
\end{abstract}

INDEX TERMS: Corynebacterium pseudotuberculosis, sheep, lymphadenitis, lymph nodes, fine needle aspiration, aspiration biopsy.

RESUMO.- O presente estudo investigou o uso da citologia aspirativa com agulha fina no diagnóstico da linfadenite em ovinos e a ocorrência de microrganismos nos linfonodos com lesões, com ênfase no isolamento de Corynebacterium pseudotuberculosis. Foram utilizados 100 linfonodos de ovinos com aumento de volume sugestivos de linfadenite e 100 linfonodos de ovinos sem lesões, colhidos em abatedouro. C. pseudotuberculosis

\footnotetext{
${ }^{1}$ Recebido em 2 de fevereiro de 2011.

Aceito para publicação em 20 de junho de 2011.

${ }^{2}$ Enfermidades Infecciosas dos Animais, Departamento de Higiene Veterinária e Saúde Pública, Faculdade de Medicina Veterinária e Zootecnia, Universidade Estadual Paulista (Unesp), Cx. Postal 560, Botucatu, SP 18618970, Brasil. *Autor para correspondência: mgribeiro@fmvz.unesp.br

${ }^{3}$ Disciplina de Produção Animal, Faculdade de Tecnologia (Fatec), Av. José Ítalo Bacchi s/n, Botucatu, SP 18606-855.

${ }^{4}$ Curso de Medicina Veterinária, Universidade do Oeste Paulista (Unoeste), Rodovia Raposo Tavares, Km 572, Presidente Prudente, SP 19067175, Brasil.
}

(73,0\%), Arcanobacterium pyogenes (6,0\%), Streptococcus spp. $\beta$ hemolítico $(5,0 \%)$ e Escherichia coli $(4,0 \%)$ foram os microrganismos mais frequentes nos animais com linfadenite. Streptococcus spp. $(21,0 \%)$ e Staphylococcus spp. $(7,0 \%)$ foram as bactérias isoladas com maior frequência nos linfonodos sem lesões colhidos em abatedouro. A punção aspirativa com agulha fina permitiu identificar microrganismos "corineformes" em 79 $(79,0 \%)$ animais com linfadenite e, destes, $73(73,0 \%)$ foram identificados como C. pseudotuberculosis. Nenhuma linhagem de C. pseudotuberculosis foi isolada dos linfonodos dos animais sem lesões. Concluiu-se que C. pseudotuberculosis foi o microrganismo mais freqüente nos ovinos com linfadenite, e que a citologia aspirativa pode ser utilizada como método de triagem no diagnóstico da linfadenite caseosa ovina.

TERMOS DE INDEXAÇÃO: Corynebacterium pseudotuberculosis, ovino, linfadenite, punção aspirativa com agulha fina. 


\section{INTRODUÇÃO}

A criação de ovinos destinados à produção de carne, lã e leite vem aumentando significativamente em todo o mundo. Estima-se que somente o rebanho ovino mundial destinado à produção leiteira compreenda mais de 100 milhões de cabeças (FAO 2001). No Brasil, a criação comercial de ovinos é praticada em quase todos os estados da Federação. Historicamente foi mais desenvolvida nos estados do nordeste e sul. Nas últimas décadas tem-se expandido para as regiões sudeste e centro-oeste. Particularmente no estado de São Paulo, a criação de ovinos experimentou aumento significativo nos últimos anos, estimulada pela introdução de novas raças para a produção principalmente de carne e leite (Domingues \& Langoni 2001, Carvalho et al. 2008).

Diferentes fatores sanitários são responsabilizados pela redução da produtividade de ovinos, dentre os quais se destaca a linfadenite caseosa. A doença causa graves prejuízos aos criatórios, determinados pela depreciação da pele e lã, queda na produção de leite e carne, descarte de carcaças, bem como pela morte ocasional de animais (Williamson 2001).

A linfadenite caseosa é reconhecida como doença crônica em pequenos ruminantes domésticos causada principalmente pelo Corynebacterium pseudotuberculosis ( $C$. pseudotuberculosis). No entanto, outros microrganismos como Mannheimia (Pasteurella) haemolytica, Arcanobacterium pyogenes, Pseudomonas aeruginosa, enterobactérias e os gêneros Staphylococcus e Streptococcus, também estão envolvidos na gênese da linfadenite infecciosa em ovinos (Ribeiro et al. 2001, Pugh 2005).

A doença se caracteriza clinicamente pela formação de abscessos, particularmente em linfonodos submandibulares, pré-escapulares, pré-femorais, supramamários e poplíteos (Motta et al. 2010). Paralelamente, em certos animais o microrganismo não fica restrito aos linfonodos superficiais e se dissemina para diversos órgãos, por via linfohemática, causando pneumonia, piotórax, linfadenite (mesentérica, mediastínica, pré-hepática), pielonefrite, peritonite, hepatite, miocardite, encefalite e/ou abscessos em outros órgãos. Os animais com disseminação da bactéria por via linfohemática tendem a desenvolver a forma crônica da doença, caracterizada por emagrecimento e debilidade progressiva, também denominada "forma visceral" ou "síndrome da ovelha magra" (Riet-Correa 2001, Pugh 2005, Radostits et al. 2007). C. pseudotuberculosis é eliminado pela secreção purulenta de linfonodos abscedados, descargas oronasais e, ocasionalmente, pelo leite. A veiculação da bactéria ocorre predominantemente por contaminação de soluções de continuidade da pele após práticas rotineiras de manejo como tosquia, corte de cauda, banhos de imersão, corte de umbigo (Pugh 2005), por lesões na pele por forragens pontiagudas (Riet-Correa 2001), ou abrasões na região de pescoço em instalações providas de canzil (Ribeiro et al. 2001).

Diferentes métodos diagnósticos têm sido utilizados na linfadenite caseosa em pequenos ruminantes que incluem testes sorológicos (soroneutralização, imunodifusão em gel de ágar, hemaglutinação indireta, fixação de complemento, ELISA), de imunidade mediada por células (testes alérgicos) e, recentemente, técnicas de biologia molecular, como a reação em cadeia pela polimerase [PCR] (Dorella et al. 2006, Pacheco et al. 2007). No entanto, a dificuldade de utilização dos testes sorológicos visando o descarte individual dos animais soropositivos, ou mesmo a ocorrência de reações inespecíficas, tem limitado o uso destes testes na rotina diagnóstica. Com efeito, na prática, o isolamento microbiano de C. pseudotuberculosis a partir do material purulento de linfonodos, abscessos e/ou órgãos permanece como o procedimento mais fidedigno na rotina de diagnóstico "in vivo" (Ribeiro et al. 2001).

Visando aprimorar o controle sanitário da linfadenite caseosa no estado de São Paulo foi instituída a citologia aspirativa com agulha fina (CAAF) como método de diagnóstico de triagem da doença à admissão de ovinos nas exposições ranqueadas da Associação Paulista de Criadores de Ovinos [Aspaco] (Oliveira 2009). Desde 2003, o uso da CAAF à admissão das exposições tem impedido a entrada e/ou a permanência de animais com aumento de linfonodos superficiais, que, após a citoaspiração, revelem microrganismos "corineformes", se caracterizando como medida adicional de sanidade no controle da doença em eventos no estado de São Paulo.

0 presente estudo investigou a citologia aspirativa com agulha fina no diagnóstico da linfadenite e a ocorrência de microrganismos em linfonodos de ovinos com e sem lesões.

\section{MATERIAL E MÉTODOS}

Foram utilizados 100 ovinos de diferentes criatórios localizados na região centro-oeste do estado de São Paulo, apresentando aumento de linfonodos superficiais ou "palpáveis" (submandibulares, parotídeos, pré-femorais, poplíteos, pré-escapulares), sugestivos de linfadenite. Procedeu-se a colheita do conteúdo dos linfonodos com linfadenite visando o diagnóstico microbiológico e citológico, utilizando a punção aspirativa, em duplicata, pela técnica de CAAF (Guedes et al. 1997, Domingues 1999). A aspiração do material foi realizada com o citoaspirador de Valeri ${ }^{\circledR 5}$, utilizando agulhas hipodérmicas $(30 \times 7 \mathrm{~mm})$, seringas descartáveis e individuais para cada colheita. 0 primeiro material colhido pela CAAF, de cada linfonodo, contido tanto no canhão da agulha quanto na seringa foi acondicionado sob refrigeração, visando o diagnóstico microbiológico. Em seguida foi realizada nova aspiração, com vistas ao diagnóstico citológico. 0 material aspirado visando o diagnóstico citológico dos microrganismos foi imediatamente distendido em quatro lâminas de microscopia de extremidade fosca. Destas, duas lâminas foram submetidas às colorações de Gram e Panóptico (Ribeiro et al. 2001). As demais lâminas foram mantidas como reserva para métodos de coloração diferencial de microrganismos. A presença de organismos sugestivos do grupo dos "corineformes" nas colorações de Gram e/ou Panóptico foi comparada com o isolamento destes microrganismos nos meios de cultivo.

Foram colhidos também 100 linfonodos mesentéricos ou mediastínicos sem sinais de lesão, obtidos na linha de abate do

\footnotetext{
${ }^{5}$ Citoaspirador de Valeriß - MPJ Equipamentos Médicos, Ribeirão Preto, SP.
} 
frigorífico Cowpig, Boituva, SP. Os linfonodos foram mantidos congelados $\left(-20^{\circ} \mathrm{C}\right)$ até o momento do processamento microbiológico. Nestes linfonodos não foi realizado o diagnóstico citológico.

A citoaspiração dos animais com linfadenite e as colheitas dos linfonodos ao abate foram realizadas de 2009 a 2010. Foi utilizado para o estudo somente um linfonodo de cada ovino na linha de abate e também nos animais com linfadenite (aumento de volume), ainda que o mesmo apresentasse mais de um linfonodo aumentado. Não foram utilizados no estudo linfonodos abscedados para os exames microbiológicos e citológicos.

O material aspirado do interior dos linfonodos com linfadenite foi depositado assepticamente em tubos contendo caldo cérebro-coração e incubado por 12 horas, em condições de aero e microaerofilia a $37^{\circ} \mathrm{C}$. Após este período, e mediante a constatação de turvação do caldo, o material foi cultivado nos meios de ágar sangue ovino desfibrinado (5\%) e ágar MacConkey. As placas contendo os meios de ágar MacConkey e ágar sangue foram mantidas, respectivamente, por 48 horas e 96 horas, visando à identificação dos microrganismos, segundo as características morfo-tintoriais, bioquímicas e de cultivo (Quinn et al. 1994, 2005). Os 100 linfonodos colhidos na linha de abate de ovinos sem sinais aparentes de linfadenite foram descongelados e, após flambagem da superfície, foram colhidos assepticamente fragmentos do tecido (Guazzelli 2009). Este material foi semeado nos meios de ágar sangue ovino e ágar MacConkey, submetidos às mesmas condições de cultivo microbiológico supracitadas.

Visando o diagnóstico microbiológico específico de Corynebacterium pseudotuberculosis, após o cultivo microbiológico do conteúdo dos linfonodos dos animais, com e sem lesões, foi avaliada a presença de colônias diminutas $(0,5 \mathrm{~mm}$ de diâmetro), com estreito halo de beta-hemólise, ressecadas, aderidas ao meio, de coloração esbranquiçada ou opaca, após 48-72 horas no meio de ágar sangue ovino, sugestivas de isolamento do microrganismo. No entanto, o diagnóstico definitivo de C. pseudotuberculosis foi firmado nas linhagens que após a coloração de Gram revelaram a presença de organismos cocóides a pleomórficos, Gram positivos, bem como nos testes de caracterização fenotípica foram catalase positivas, oxidase negativas, urease, glicose e maltose positivas, sacarose negativas, não hidrolisaram a esculina e caseína, e que apresentaram teste de CAMP positivo frente à linhagem padrão de Rhodococcus equi (ATCC 33.701+) (Quinn et al. 1994, 2005).

A ocorrência dos diferentes microrganismos obtidos de animais com e sem linfadenite e a associação entre os resultados microbiológicos e citológicos foram comparadas pelo teste binomial com aproximação para distribuição normal, utilizando o Software Statistical Package for Social Sciences, considerando diferença significante para valores de $\mathrm{P}<0,05$ (Maroco 2007).

\section{RESULTADOS}

Dos 100 linfonodos puncionados de animais com linfadenite obteve-se o isolamento de microrganismos de origem bacteriana - em cultura pura ou em associação - em todos os espécimes. C. pseudotuberculosis foi o microrganismo mais frequente (73,0\%), seguido por Arcanobacterium pyogenes $(6,0 \%)$ e Streptococcus spp. hemolítico $(5,0 \%)$, além de outros microrganismos observados em menor freqüência (Quadro 1). Foi observada associação estatística significativa entre a presença de linfadenite e o isolamento de C. pseudotuberculosis $(\mathrm{P}<0,0001)$.
Quadro 1. Freqüência absoluta e relativa de microrganismos isolados, em cultura pura ou em associação, de 100 ovinos com linfadenite criados no centro-oeste do estado de São Paulo. Botucatu, SP, 2009-2010

\begin{tabular}{lcc}
\hline Microrganismo(s) & $\begin{array}{c}\text { Frequência } \\
\text { absoluta }\end{array}$ & $\begin{array}{c}\text { Frequência } \\
\text { relativa } \\
(\%)\end{array}$ \\
\hline Corynebacterium pseudotuberculosis & 73 & 73,0 \\
Arcanobacterium pyogenes & 6 & 6,0 \\
Streptococcus spp. (hemolítico) & 5 & 5,0 \\
Escherichia coli & 4 & 4,0 \\
Staphylococcus spp. & 2 & 2,0 \\
Streptococcus spp. & 2 & 2,0 \\
Citrobacter freundii & 2 & 2,0 \\
Staphylococcus aureus & 1 & 1,0 \\
Nocardia spp. & 1 & 1,0 \\
Enterobacter cloacae & 1 & 1,0 \\
Citrobacter diversus & 1 & 1,0 \\
Escherichia coli + Staphylococcus aureus & 1 & 1,0 \\
Escherichia coli + Streptococcus spp. $\alpha$ hemolítico & 1 & 1,0 \\
Total & 100 & 100,0 \\
\hline
\end{tabular}

$\%=$ porcentagem.

A avaliação citológica do esfregaço do conteúdo dos linfonodos com aumento de volume (linfadenite) permitiu identificar microrganismos Gram-positivos pleomórficos - ou "corineformes" - em 79 (79,0\%) amostras. Destes, em $73(73,0 \%)$ linfonodos foi isolado C. pseudotuberculosis e em seis (6,0\%) Arcanobacterium pyogenes. Os demais materiais acusaram a presença de cocos Gram positivos ou negativos (enterobactérias, Staphylococcus spp. e Streptococcus spp.), e um isolado pleomórfico ramificado, caracterizado posteriormente como Nocardia spp. Foi observada associação estatística significativa $(\mathrm{P}<0,05)$ entre o isolamento microbiológico de $C$. pseudotuberculosis e a presença de microrganismos de aspecto "corineforme" no exame citológico.

O Quadro 2 apresenta os microrganismos isolados dos 100 linfonodos dos ovinos sem lesões. Streptococcus spp. $(21,0 \%)$ e Staphylococcus spp. $(7,0 \%)$ foram os microrganismos mais frequentemente isolados dos linfonodos sem lesões, seguidos de outras bactérias em menor frequência. Não foram isoladas linhagens de $C$. pseudotuberculosis dos linfonodos sem lesões.

\section{DISCUSSÃO E CONCLUSÕES}

A linfadenite caseosa figura dentre as afeç̧ões mais frequentes na criação de pequenos ruminantes no Brasil (Dorella et al. 2006, Abreu et al. 2008, Carvalho et al. 2008). A doença se caracteriza pela formação de abscessos em linfonodos, causada predominantemente por Corynebacterium pseudotuberculosis (Dorella et al. 2006).

Nos 100 ovinos puncionados com linfadenite, C. pseudotuberculosis foi isolado em 73 linfonodos superficiais (submandibulares, parotídeos, pré-femorais, poplíteos ou pré-escapulares), reforçando o microrganismo como o mais prevalente na gênese da linfadenite infecciosa em ovelhas (Domingues \& Langoni 2001, Williamson 2001). 
Quadro 2. Frequência absoluta e relativa de microrganismos isolados, em cultura pura ou em associação, de 100 linfonodos sem lesões, obtidos de ovinos procedentes de abatedouro do interior do estado de São Paulo. Botucatu, SP, 2009-2010

\begin{tabular}{lcc}
\hline Microrganismo(s) & $\begin{array}{c}\text { Frequência } \\
\text { absoluta }\end{array}$ & $\begin{array}{c}\text { Frequência } \\
\text { relativa (\%) }\end{array}$ \\
\hline Streptococcus spp. & 21 & 21,0 \\
Staphylococcus spp. & 7 & 7,0 \\
Staphylococcus aureus & 5 & 5,0 \\
Pseudomonas aeruginosa & 1 & 1,0 \\
Pasteurella multocida & 1 & 1,0 \\
Streptococcus spp. + Staphylococcus spp. & 5 & 5,0 \\
Staphylococcus aureus + Escherichia coli & 1 & 1,0 \\
Staphylococcus spp. + Enterobacter spp. & 1 & 1,0 \\
Negativos & 58 & 58,0 \\
Total & 100 & 100,0 \\
\% $=$ porcentagem. & &
\end{tabular}

No entanto, em 27 animais foram identificados também outros microrganismos, isolados ou em associação. Este achado reforça a necessidade do diagnóstico diferencial de C. pseudotuberculosis para outros microrganismos de origem bacteriana na casuística da linfadenite em ovinos (Pugh 2005, Radostits et al. 2007).

A complicação clínica mais preocupante da linfadenite ovina é representada pela disseminação da bactéria dos linfonodos superficiais ("palpáveis") para linfonodos viscerais e/ou órgãos (Radostits et al. 2007). Nos 100 linfonodos mediastínicos e mesentéricos colhidos ao abate de ovinos no presente estudo, não foi isolada nenhuma linhagem $\operatorname{de} C$. pseudotuberculosis. Em contraste, foram identificados outros microrganismos de origem bacteriana, particularmente dos gêneros Streptococcus e Staphylococcus. A ausência do isolamento de C. pseudotuberculosis dos linfonodos mesentéricos e mediastínicos nos ovinos amostrados ao abate indica que o microrganismo infecta preferencialmente os linfonodos superficiais das ovelhas (submandibulares, parotídeos, pré-femorais, poplíteos ou pré-escapulares). Este achado sinaliza também que a forma disseminada crônica, que envolve linfonodos viscerais, provavelmente está relacionada a animais que apresentam debilidade orgânica (subnutridos, coinfecção com doenças debilitantes ou imunussupressoras), que favoreceriam o comportamento oportunista da bactéria e a disseminação linfohemática para órgãos viscerais (Motta et al. 2010).

Nas últimas décadas, vários métodos têm sido utilizados no diagnóstico da linfadenite caseosa em pequenos ruminantes, incluindo testes sorológicos, de imunidade celular e, recentemente, técnicas de biologia molecular (Dorella et al. 2006, Radostits et al. 2007). Contudo, a dificuldade da utilização dos testes sorológicos visando o descarte individual dos animais soropositivos, ou mesmo a ocorrência de reações inespecíficas, tem limitado o uso destes testes na rotina diagnóstica da doença em pequenos ruminantes. $\mathrm{Na}$ prática, o isolamento microbiano de C. pseudotuberculosis a partir do material purulento de linfonodos, abscessos e órgãos ainda representa o procedimento mais utilizado na rotina de diagnóstico (Ribeiro et al. 2001, Motta et al. 2010). Neste contexto, a CAAF tem sido utilizada nos últimos anos como método de diagnóstico de triagem da linfadenite ca- seosa em exposições de ovinos no estado de São Paulo e tem impedido a entrada e/ou a permanência de animais com a doença nos recintos (Motta et al. 2010). Estudo realizado em 2009 comparou a CAAF, o exame microbiológico, ELISA e PCR no diagnóstico da linfadenite caseosa em 26 ovinos sintomáticos (linfonodos enfartados e abscedados) e em 129 assintomáticos, e observou alta especificidade do cultivo bacteriano $(98,0 \%)$ e do método citológico $(94, \%)$ (Ribeiro 2009).

Ribeiro et al. (2001) utilizaram pela primeira vez no estado de São Paulo a CAAF no diagnóstico da linfadenite caseosa em 11 caprinos. A partir do material aspirado de linfonodos foi possível isolar C. pseudotuberculosis em sete amostras de material purulento obtidas destes caprinos, bem como visualizar microrganismos "corineformes" corados pelos métodos de Gram e Giemsa. Os autores enfatizaram que a técnica se mostrou de fácil execução, de baixo custo e de reduzida agressão tecidual se comparada a outras técnicas de diagnóstico em tecidos, como a histopatologia. No presente estudo, a avaliação citológica do conteúdo dos linfonodos aumentados, corados pelos métodos de Gram e Panóptico, permitiu identificar microrganismos "corineformes" em 79 espécimes de linfonodos, dos quais 73 linhagens foram identificadas como C. pseudotuberculosis e seis como Arcanobacterium pyogenes. Este resultado ressalta que a CAAF permitiu o diagnóstico presuntivo acurado da linfadenite por C. pseudotuberculosis em 73\% dos ovinos, permitindo, consequentemente, a adoção precoce de medidas de profilaxia e controle nos criatórios acometidos. Ademais, atesta que a CAAF se mostra eficiente como método de triagem na rotina de admissão de animais em exposições e feiras, possibilitando impedir a entrada de animais que acusarem a presença de microrganismos "corineformes" nos esfregaços de linfonodos aumentados à palpação, ou isolar estes animais dos demais nos recintos (Oliveira 2009), até que se proceda à confirmação diagnóstica microbiológica ou por outros métodos mais específicos, como a PCR.

Faz-se necessário ressaltar que em seis ovelhas com linfadenite foi diagnosticada na CAAF, a presença de organismos pleomórficos, "corineformes", com isolamento microbiano de Arcanobacterium pyogenes. Tal inespecificidade da CAAF observada em $6 \%$ dos animais amostrados é esperada, visto que na morfologia à microscopia C. pseudotuberculosis e Arcanobacterium pyogenes são praticamente indistinguíveis (Ribeiro et al. 2001, Motta et al. 2010). No entanto, tal limitação não inviabiliza o uso desta técnica citológica, visto que, em geral, Arcanobacterium pyogenes apresenta baixa frequência na casuística da linfadenite em pequenos ruminantes. Ademais, foi estatisticamente significante a associação entre o resultado microbiológico e o citológico nos animais amostrados com linfadenite infectados por C. pseudotuberculosis. Este achado reforça que a associação da CAAF com o cultivo microbiológico do material dos aspirados de linfonodos possibilita o incremento da eficiência do diagnóstico citológico da linfadenite em ovinos.

Agradecimentos.- À Fundação de Amparo à Pesquisa do Estado de São Paulo (FAPESP) pelo suporte financeiro e concessão de bolsa de iniciação científica para a acadêmica Alexandra Frey Belotta (FAPESP 2009/53315-3). 


\section{REFERÊNCIAS}

Abreu S.R.O., Mota, R.A., Pinheiro Junior J.W.P., Rosinha G.M.S. \& Castro R.S. 2008. Perfil de sensibilidade antimicrobiana in vitro de isolados de Corynebacterium pseudotuberculosis de caprinos e ovinos com linfadenite caseosa no sertão de Pernambuco, Brasil. Vet. Zootec., Botucatu, 15(3):502-509.

Carvalho E.B., Oliveira M.A.G. \& Domingues P.F. 2008. Base para criação de

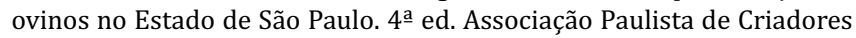
de Ovinos (Aspaco), São Manuel. 118p.

Domingues P.F. 1999. Estudo de parâmetros de constituintes do leite e plasma sanguíneo, possível associação do polimorfismo genético-bioquímico das beta-globulinas e transferrinas e exame citológico nas mastites bovinas subclínicas. Tese de Doutorado, Faculdade de Medicina Veterinária e Zootecnia, Universidade Estadual Paulista, Botucatu, SP. $121 \mathrm{p}$.

Domingues P.F. \& Langoni H. 2001. Manejo Sanitário Animal. Editora de Publicações Biomédicas, Rio de Janeiro. 210p.

Dorella F.A., Pacheco L.G.C., Oliveira S.C., Miyoshi A. \& Azevedo V. 2006. Corynebacterium pseudotuberculosis: Microbiology, biochemical properties, pathogenesis and molecular studies of virulence. Vet. Res. 37:201-218.

FAO 2001. Produção de leite no mundo em 2001. Food and Agricultural Organization, Rome. Disponível em <http://japy.com/htmlgb/lait/monde. $\mathrm{htm}>$ Acesso em 24 maio 2004.

Guazzelli A. 2009. Virulência de linhagens de Rhodococcus equi isoladas de linfonodos de suínos e javalis (Sus scrofa) de abatedouros. Dissertação de Mestrado, Faculdade de Medicina Veterinária e Zootecnia, Universidade Estadual Paulista, Botucatu, SP. 55p.

Guedes R.C.M., Nogueira R.H.G. \& Tudury E.A. 1997. Diagnóstico citológico de lesões proliferativas e inflamatórias através da técnica de punção de tecidos com agulha fina. Hora Vet. 96:15-21.

Maroco J. 2007. Análise Estatística com Utilização do SPSS. 3a ed. Símbolo, Lisboa. 824p.
Motta R.G., Cremasco A.C.M. \& Ribeiro M.G. 2010. Infecções por Corynebacterium pseudotuberculosis em animais de produção. Vet. Zootec. 17:200-213.

Oliveira M.A.G. 2009. Punção aspirativa aumenta o controle sanitário da linfadenite caseosa em exposições de ovinos no estado de São Paulo. 0 Ovelheiro 13(78):11.

Pacheco L.G.C., Pena R.R., Castro T.L.P., Dorella F.A., Bahia R.C., Carminati R., Frota M.N.L., Oliveira S.C., Meyer R., Alves F.S.F., Miyoshi A. \& Azevedo V. 2007. Multiplex PCR assay for identification of Corynebacterium pseudotuberculosis from pure cultures and for rapid detection of this pathogen in clinical samples. J. Med. Microbiol. 56:480-486.

Pugh D.G. 2005. Clínica de Ovinos e Caprinos. Roca, São Paulo, p.232-233.

Quinn P.J., Carter M.E., Markey B. \& Carter G.R. 1994. Clinical Veterinary Microbiology. Wolfe, London, p.137-143.

Quinn P.J., Markey B.K., Carter M.E., Donnelly W.J. \& Leonard F.C. 2005. Rhodococcus equi, p.71-73. In: Ibid. (Eds), Microbiologia Veterinária e Doenças Infecciosas. Artmed, Porto Alegre.

Radostits O.M., Gay C.C., Hinchcliff K.W. \& Constable P.D. 2007. Veterinary Medicine: A textbook of the diseases of cattle, horses, sheep, pigs, and goats. $10^{\text {th }}$ ed. W.BG. Saunders, Philadelphia, p.795-798.

Ribeiro D. 2009. Análise comparativa de métodos de diagnóstico para linfadenite caseosa em ovinos sintomáticos e assintomáticos. Dissertação de Mestrado, Curso de Medicina Veterinária, Faculdade de Odontologia, Universidade Estadual Paulista, Araçatuba, SP. 53p.

Ribeiro M.G., Dias Júnior J.G., Paes A.C., Barbosa P., Nardi Júnior G. \& Listoni F.J.P. 2001. Punção aspirativa com agulha fina no diagnóstico de Corynebacterium pseudotuberculosis na linfadenite caseosa caprina. Arqs Inst. Biológico, São Paulo, 68(1):23-28.

Riet-Correa F. 2001. Linfadenite caseosa, p.284-288. In: Riet-Correa F., Schild A.L., Méndez M.D.C. \& Lemos R.A.A. (Eds), Doenças de Ruminantes e Eqüinos. Varela, São Paulo

Williamson L.H. 2001. Caseous lymphadenitis in small ruminants. Vet. Clin. North Am., Food Anim. Pract. 17(2):359-371. 